This document is confidential and is proprietary to the American Chemical Society and its authors. Do not copy or disclose without written permission. If you have received this item in error, notify the sender and delete all copies.

\title{
Fragmentation and Distortion of Terpyridine-Based Spin- Crossover Complexes on Au(111)
}

\begin{tabular}{|r|l|}
\hline Journal: & The Journal of Physical Chemistry \\
\hline Manuscript ID & jp-2018-112423.R2 \\
\hline Manuscript Type: & Article \\
\hline Author: & 25-Jan-2019 \\
\hline Complete List of Authors: & $\begin{array}{l}\text { Knaak, Thomas; Christian-Albrechts-Universitat zu Kiel, IEAP } \\
\text { Gonzalez, Cesar; Universidad de Granada, Electronics and Computer } \\
\text { Technology } \\
\text { Dappe, Yannick; CNRS, SPEC/SPCSI } \\
\text { Harzmann, Gero; Universitat Basel, Department of Chemistry } \\
\text { Brandl, Thomas; Universitat Basel, Department of Chemistry } \\
\text { Mayor, Marcel; Universitat Basel, Department of Chemistry } \\
\text { Berndt, Richard; Christian-Albrechts-Universitat zu Kiel Sektion Physik, } \\
\text { IEAP } \\
\text { Gruber, Manuel; Christian-Albrechts-Universitat zu Kiel, IEAP }\end{array}$ \\
\hline
\end{tabular}

\section{SCHOLARONE" Manuscripts}




\begin{abstract}
Spin-crossover complexes are attractive for their spinswitching functionality. However, only few compounds have been found to remain intact in direct contact to metal surfaces. For the design of new spin-crossover complexes, it is important to understand the mechanisms leading to fragmentation. Here, we investigate, using low-temperature scanning tunneling microscopy along with density functional theory calculations, two $\mathrm{Fe}$ (terpyridine) $)_{2}$ complexes deposited on $\mathrm{Au}(111)$ by electrospray ionization with in-line mass selection. Only fragments of the first compound are observed on the surface, while the second compound is strongly flattened. Based on a detailed analysis of the adsorbates on the surface, possible mechanisms for the fragmentation and molecular distortion are proposed.
\end{abstract}

\section{Introduction}

Spin-crossover (SCO) complexes are particularly interesting for applications because of their intrinsic spin switching functionality. ${ }^{1-11}$ Considerable effort has been made to prepare such complexes on surfaces, e.g. for electrical contacting. ${ }^{12-28}$ To enable physical vapor deposition, which is the most common technique for obtaining high-quality films, compounds with increased thermal stability have been synthesized. ${ }^{12-37}$ However, even for such robust compounds, fragmen- tation issues have been reported. For instance, while the intactness of $\left[\mathrm{Fe}\left(\mathrm{H}_{2} \mathrm{~B}(\mathrm{pz})_{2}\right)_{2}\left(\right.\right.$ phenme $\left.\left._{4}\right)\right]$ (phemne 4 $=3,4,7,8$-tetramethyl-1,10-phenanthroline) has been demonstrated on $\operatorname{Bi}(111)$, the molecules fragment on $\mathrm{Au}(111) .{ }^{26}$ For the design of new robust SCO compounds, it therefore appears essential to not only consider the gas-phase stability but also to further understand fragmentation processes of complexes deposited on surfaces.

In the present study, we investigate the deposition of two $\mathrm{Fe}$ (terpyridine) $)_{2}$ complexes $\mathbf{1}$ and $\mathbf{2}$ with terpyridine-based ligands on $\mathrm{Au}(111)$ using lowtemperature scanning tunneling microscopy (STM), density functional theory (DFT) and molecular dynamics calculations. We used electrospray ionization (ESI) deposition with in-line mass selection, from which the integrity of the molecules in the gas phase is ensured. However, on the $\mathrm{Au}(111)$ surface, only terpyridine (tpy) ligands and $\mathrm{Fe}$ adatoms, i.e. fragments of complex $\mathbf{1}$, are observed. By a statistical analysis of the adsorption conformers (in the following referred to just as conformers) of the tpy ligands compared to the energies at play as inferred from DFT calculations, the conformational change of the tpy ligand as well as the fragmentation of the complex is found to occur at the early instants of the adsorption, presumably due to the population of high-energy vibrational modes in the molecules. These considerations were taken into account for the design of complex $\mathbf{2}$, whose ligand system indeed does not dissociate upon adsorption. However, presumably due to the 
large van der Waals forces, the complex is strongly flattened and the octahedral cage of the Fe ion is deformed. While the integrity of these two complexes is lost upon adsorption, the detailed analysis presented in this study allows to identify important ingredients for the design of new SCO complexes with increased robustness.

\section{Experimental details}

\section{Synthesis}

Complexes 1 and $\mathbf{2}$ (Fig. 1) were synthesized following Refs. 38,39, based on the synthesis described in Refs. 40,41 .

\section{Sample preparation}

Clean $\mathrm{Au}(111)$ surfaces were prepared by cycles of $\mathrm{Ar}^{+}$sputtering at $1.3 \mathrm{kV}$ and annealing to $500^{\circ} \mathrm{C}$. The molecules were deposited using a home-built massselective electrospray ionization deposition setup described in Ref. 42 and previously successfully employed for other complexes. ${ }^{22,43-45}$ Stable spray conditions were achieved with the molecules dissolved in acetonitrile. The deposition of the Fe(tpy) $)_{2}$ complexes $\mathbf{1}(\mathbf{2})$ was performed by selecting a mass-to-charge ratio of $515 \mathrm{u} / \mathrm{e}(459 \mathrm{u} / \mathrm{e})$ at a relative kinetic energy of approximately $3 \mathrm{eV}(10 \mathrm{eV})$. The spray voltage was $3.8 \mathrm{kV}$. During deposition, the pressure in the preparation chamber stayed below $2 \times 10^{-9}$ mbar and the substrates were kept at room temperature.
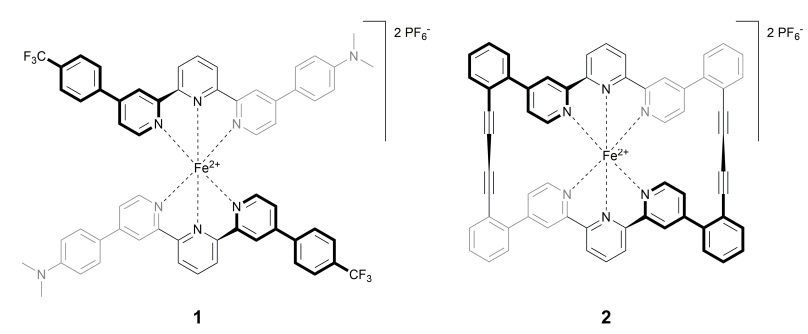

Figure 1: Structures of the two Fe-tpy complexes 1 and 2.

\section{STM measurements}

Experiments were performed with a STM operating in ultrahigh vacuum at $5 \mathrm{~K}$. STM tips were electrochemically etched from a tungsten wire and further prepared in situ by indentation into the substrate. All STM topographs were acquired in the constant-current mode. Differential conductance spectra were acquired using a lock-in amplifier (modulation amplitude of $20 \mathrm{mV}$ at frequencies close to $1 \mathrm{kHz}$ ) while the STM feedback loop was open. The images were processed with WSxM. ${ }^{46}$

\section{DFT and molecular-dynamics calcula- tions}

DFT calculations were carried out with the localizedorbital molecular-dynamics package Fireball. ${ }^{47}$ This approach has already proven to yield good results on molecular systems. ${ }^{48}$ Standard optimized basis sets for $\mathrm{H}, \mathrm{C}, \mathrm{N}, \mathrm{F}$ and $\mathrm{Au}$ were used, as already considered in reported studies. ${ }^{49}$

First, structural optimizations were performed for tpy ligands in gas phase until forces reached values lower than $0.1 \mathrm{eV} \AA^{-1}$ to obtain the total energy of each ligand as well as their equilibrium configurations. Then energies of the tpy ligand conformers on a $\mathrm{Au}(111)$ surface were calculated using the LCAO-S2+vdW formalism which takes into account van der Waals interactions. ${ }^{50}$ Each ligand has been calculated on a $10 \times 10$ slab of gold atoms in the $x y$ plane, made of three atomic layers in the $z$ direction. From the obtained adsorbed configurations, we calculated the corresponding STM images using a Keldysh-Green formalism. ${ }^{51}$ Finally, in order to test the stability of the different ligands in the gas phase, we performed molecular dynamics calculations using the Fireball code at 300 and $600 \mathrm{~K}$.

\section{Results \& discussion}

The molecular structure of complex $\mathbf{1}$ is presented in Figure 1. Two 2,2':6',2'-terpyridine ligands are connected to a central iron atom. The ligands are asymmetric with two different substituents, namely 4-(trifluoromethyl)phenyl and 4-N,N-dimethylaniline. The intention was to profit from the dipolar tpy ligands in the complex as potential E-field sensitive SCO switching mechanism. Similar complexes have been investigated in controlled break-junction experiments. ${ }^{41,52}$

Complex 1 was deposited on $\mathrm{Au}(111)$ using ESI. Prior to deposition, the molecular ion beam was analyzed by an in-line quadrupole mass spectrometer. The inset to Figure 2 shows a typical mass spectrum. A well-pronounced peak is observed corresponding to the doubly charged, intact compound $\mathbf{1}$ (calculated $\mathrm{m} / \mathrm{z}$ of $524 \mathrm{u} / \mathrm{e}$ ). An additional small peak, may be assigned to single, singly charged tpy ligands attached to Fe (calculated $m / z$ of $552 \mathrm{u} / \mathrm{e}$ ). This indicates that a small fraction $(<10 \%)$ of the complexes dissociates during spraying. The quadrupole was then configured to only transmit the intact $\mathbf{1}$ ions.

Figure 2 shows a typical large-scale STM topograph of a $\mathrm{Au}(111)$ surface upon ESI deposition of the $\mathrm{Fe}(\text { tpy })_{2}$ complex 1. The herringbone reconstruction of the clean $\mathrm{Au}(111)$ surface is clearly discernible as bright lines on a blue background. Disordered clusters consisting of different molecular structures are observed. The most common structure has an elongated shape with a length of $\approx 3 \mathrm{~nm}$ and an apparent height of $\approx 150 \mathrm{pm}$. These structures correspond to tpy ligands, indicating that the molecules are fragmented on the $\mathrm{Au}(111)$ surface. 


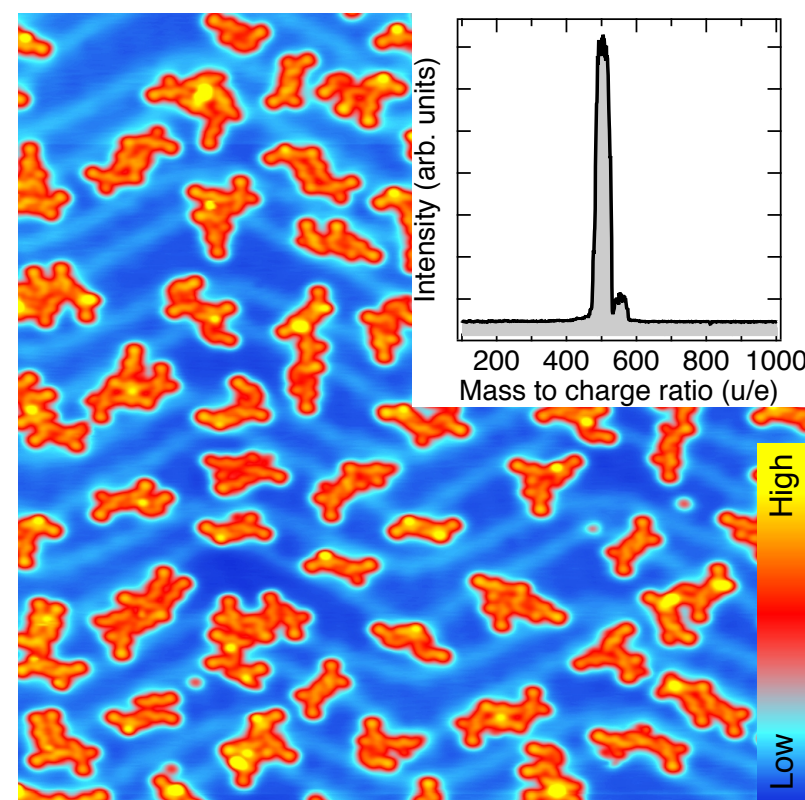

Figure 2: Large-scale STM topograph $(V=0.1 \mathrm{~V}$, $I=75 \mathrm{pA}, 50 \mathrm{~nm}$ wide) upon deposition of complex 1 on $\mathrm{Au}(111)$. The color scale ranges from 0 to $230 \mathrm{pm}$. The inset shows a typical mass spectrum of electrosprayed complex 1. Two peaks centered at $m / z=505$ and $555 \mathrm{u} / \mathrm{e}$ are resolved. To maximize ion transmission, the mass spectrometer was operated at a low resolution. This leads to a large peak width (approximately $40 \mathrm{u} / \mathrm{e}$ ) and a deviation of the measured and calculated charge-to-mass ratios. The first peak corresponds to intact, doubly charged $\mathbf{1}$ (calculated charge-to-mass ratio of $524 \mathrm{u} / \mathrm{e})$.

As detailed below, different conformations of the tpy ligands are observed. The asymmetry of the tpy ligands is essential for an accurate identification of the different conformers. Figures $3 \mathrm{a}$ and $\mathrm{b}$ show two tpy ligands lying flat on the $\mathrm{Au}(111)$ surface. Additional protrusions are observed at the side of each tpy ligand (black dots in Figure 3a). They are attributed to single Fe atoms resulting from the fragmentation of $\mathbf{1}$. This is motivated by (i) the apparent height of the protrusion (between 130 and $160 \mathrm{pm}$ at $V=100 \mathrm{mV}$ ) similar to that reported for $\mathrm{Fe}$ adatom on $\mathrm{Au}(111)(\approx 130 \mathrm{pm})^{53}$ and (ii) a statistical evaluation of the densities of Fe atoms and tpy ligands (discussed below), from which a stochiometry of 1:2.04 is extracted. This is very close to the expected stochiometry (1:2) of the $\mathrm{Fe}(\mathrm{tpy})_{2}$ molecules in the gas phase. The Fe atoms lie close to the coordination site of the three nitrogen atoms of the tpy ligand. The separation of the central $\mathrm{N}$ atom and the $\mathrm{Fe}$ atom is of the order of $0.5 \mathrm{~nm}$, i.e. larger than the $\mathrm{Fe}-\mathrm{N}$ bond length in the gas phase $(\approx 190 \mathrm{pm})$.

Before further characterizing the protrusion interpreted as Fe atoms, we focus on the tpy ligands. At a sample voltage of $-1.4 \mathrm{~V}$ (Fig. 3a), the extremities of the tpy ligands exhibit different apparent heights. This asymmetry in the topograph is due to the electronic
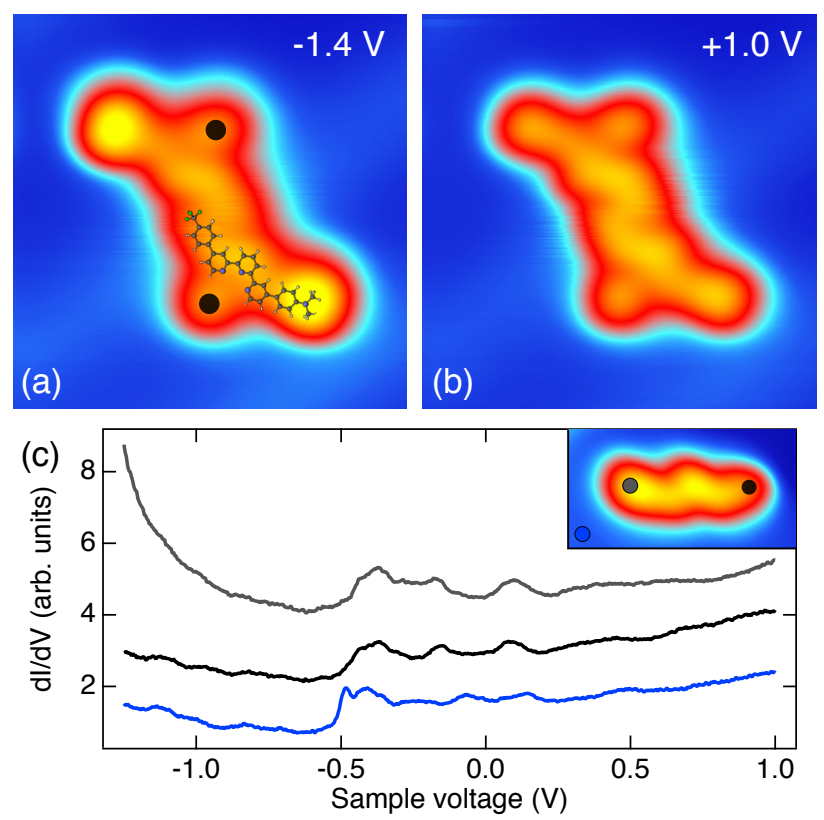

(d)

(e)

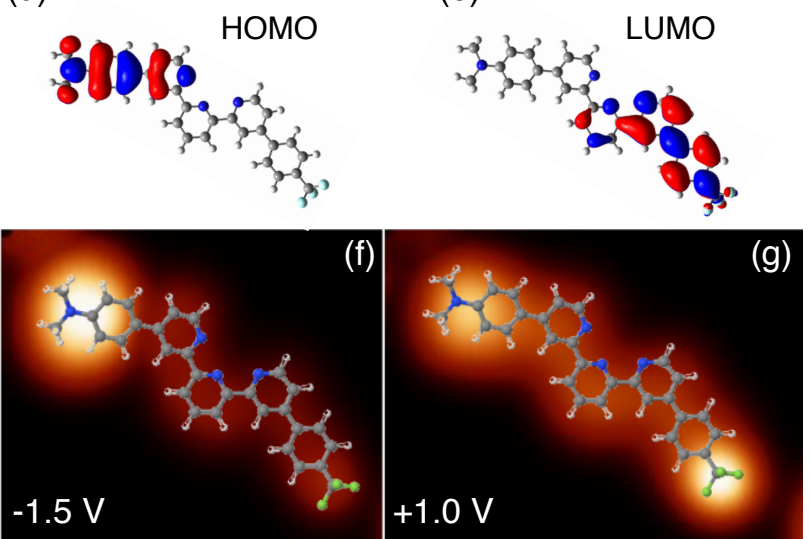

Figure 3: Identification of substituents. STM topographs (width: $5.5 \mathrm{~nm}$ ) of two tpy ligands acquired with sample voltages of (a) $-1.4 \mathrm{~V}$ and (b) $1.0 \mathrm{~V}$. A molecular model is superimposed on the image. Black disks indicate $\mathrm{Fe}$ adatoms. (c) $d I / d V$ spectra acquired over $\mathrm{Au}(111)$ and the two extremities of a single tpy ligand as indicated in the inset. The spectra are vertically shifted for clarity. (d) HOMO and (e) LUMO of a single tpy ligand as obtained from gas-phase calculations. STM simulated images at (f) $-1.5 \mathrm{~V}$ and (g) $1.0 \mathrm{~V}$.

structure as it is no more visible at a sample voltage of $+1.0 \mathrm{~V}$ (Fig. $3 \mathrm{~b}$ ). Spectra of the differential conductance $(d I / d V)$ were acquired over the $\mathrm{Au}(111)$ substrate (blue curve in Fig. 3c) and over the two extremities of a single tpy ligand (black and gray curves). The $\mathrm{Au}(111)$ surface state onset is clearly visible in all spectra. The onset of a highest occupied molecular orbital (HOMO) is observed only in the spectrum acquired over the higher lobe of the tpy ligand. The apparent height difference may therefore be attributed to the HOMO of the ligand. Gas-phase DFT calculations reveal that the HOMO extends over half of the tpy ligand with the dimethylaniline substituents (Fig. 3d) while the LUMO 
is located on the other half (Fig. 3e). Simulated STM topographs of tpy/Au(111) reproduce that the dimethylaniline substituted extremity appears higher (Fig. 3f) and that the contrast between the two extremities almost vanishes at $+1.0 \mathrm{~V}$. From additional STM measurements and simulations, we determined that the height asymmetry is discernible up to $V \approx 0.5 \mathrm{~V}$.
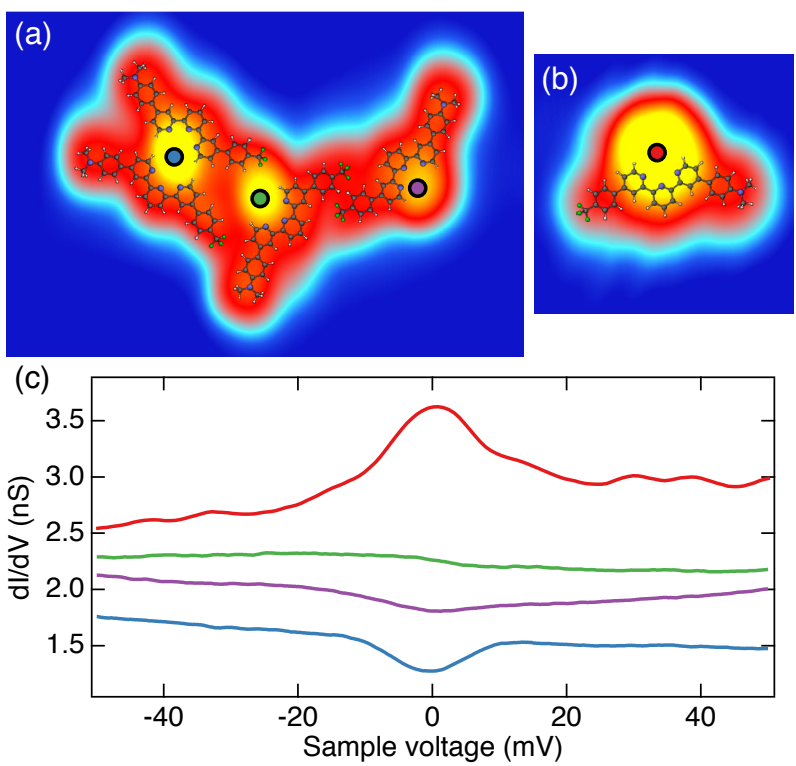

Figure 4: (a-b) STM images of tpy ligands along with Fe atoms on $\mathrm{Au}(111)$. Molecular models are overlaid. The color scale ranges over 200 pm. Image widths: (a) $6.6 \mathrm{~nm}$ and (b) $3.3 \mathrm{~nm}$. Tunneling parameters: (a) $I=$ $50 \mathrm{pA}, V=50 \mathrm{mV}$ and (b) $I=20 \mathrm{pA}, V=100 \mathrm{mV}$. (c) Low-pass filtered scanning tunneling spectra acquired atop the positions marked in (a) and (b) with dots in matching colors. The upper and lower curves exhibit zero-bias features compatible with a Kondo resonance. The zero-bias features are broadened by the modulation voltage used (amplitude $V_{m}=5.7 \mathrm{mV}$ for the top curve, $7 \mathrm{mV}$ for the others). ${ }^{54}$ The green curve is vertically shifted by $+0.3 \mathrm{nS}$ for clarity.

Figures $4 \mathrm{a}-\mathrm{b}$ show that the Fe atoms next to the tpy ligands exhibit different apparent heights and widths. Accordingly, different spectroscopic features are observed (Fig. 4c). While the green and violet spectra are relatively featureless, the red and blue spectra exhibit a peak and a dip close to the Fermi level, compatible with a Kondo resonance. We recall that no such feature has been observed from single $\mathrm{Fe}$ adatoms on $\mathrm{Au}(111)$ at $5 \mathrm{~K}$ (Ref. 55), while Fe atoms embedded in a coordination cage may lead to a Kondo resonance on $\mathrm{Au}(111)$ (Refs. 21,56). We hint that different Fe atoms are subject to different ligand fields with different degrees of bonding to the neighboring $\mathrm{N}$, for instance because of varying $\mathrm{Fe}-\mathrm{N}$ separations. This is consistent with the presence/absence of a Kondo resonance as well as the change of its line shape as (i) the ligand field dictates the occupancy of the Fe orbitals and (ii) the strength of the $\mathrm{Fe}-\mathrm{N}$ bonding may influence the electronic coupling between the Fe and the substrate. A quantitative analysis of the interplay between $\mathrm{Fe}-\mathrm{N}$ distance and spectroscopic feature is challenging because (i) the precise position of the $\mathrm{Fe}$ atom is difficult to determine when its apparent size is large (e.g. Fig. 4b) and (ii) the environment of the $\mathrm{Fe}$ atom varies (e.g. the three Fe atoms in Fig. 4 have different environments). It is worth mentioning that hydrogenation may also affect the topographic and spectroscopic properties of Fe adatoms. ${ }^{57}$

Now that the two extremities of the tpy ligands can be distinguished and identified, we discuss different conformers found on the surface. Figure 5 a shows the most common conformer. As sown in Figure 5d, the two arms of the tpy ligand are in a cis conformation relative to the central pyridine. The second most common conformation is shown in Figure 5b. The arm with the trifluoromethyl $\left(\mathrm{CF}_{3}\right)$ substituent is in a trans conformation (Fig. 5e). Finally, we observed the conformation of Figure $5 \mathrm{c}$, where the two arms adopt a trans conformation (Fig. 5e). The conformations shown in Figures $5 \mathrm{a}-\mathrm{c}$ are hereafter denoted $\mathrm{CC}, \mathrm{C}_{\mathrm{M}} \mathrm{T}_{\mathrm{F}}$ and TT, respectively. Surprisingly, the $\mathrm{C}_{\mathrm{F}} \mathrm{T}_{\mathrm{M}}$ conformation, where the arm with the trifluoromethyl (dimethylaniline) substituent is in a cis (trans) conformational form, was not observed.

We identified the conformation of 1021 ligands out of which $49 \%$ have an $\mathrm{Fe}$ adatom in the vicinity. These ligands are exclusively in the $\mathrm{CC}$ form and we therefore assume that the proximity of the Fe adatom stabilizes the $\mathrm{CC}$ conformation. The remaining $51 \%$ of the ligands are found in the $\mathrm{CC}(32 \%), \mathrm{C}_{\mathrm{M}} \mathrm{T}_{\mathrm{F}}(15 \%)$, TT (4\%) conformations. The stochiometry of Fe atoms relative to tpy ligands (1:2.04) independently evidences that $\mathrm{Fe}(\mathrm{tpy})_{2}$ molecules are deposited on the surface and that the fragmentation takes place on or close to the $\mathrm{Au}(111)$ surface.

We performed DFT calculations for the different tpy conformers using the Fireball code and the LCAO$\mathrm{S}^{2}+\mathrm{vdW}$ formalism (Tab. 1). In the gas phase, $\mathrm{CC}$ is the energetically least favorable conformation, followed by $\mathrm{T}_{\mathrm{M}} \mathrm{C}_{\mathrm{F}}, \mathrm{C}_{\mathrm{M}} \mathrm{T}_{\mathrm{F}}$ and $\mathrm{TT}$. Upon adsorption on $\mathrm{Au}(111), \mathrm{T}_{\mathrm{M}} \mathrm{C}_{\mathrm{F}}$ is the conformation with the highest energy, i.e., the least favorable. This is in agreement with the absence of the $\mathrm{T}_{\mathrm{M}} \mathrm{C}_{\mathrm{F}}$ conformer from STM images. In view of the apparent resemblance of the $\mathrm{C}_{\mathrm{M}} \mathrm{T}_{\mathrm{F}}$ and $\mathrm{T}_{\mathrm{M}} \mathrm{C}_{\mathrm{F}}$ conformers in the vicinity of the pyridine, it nonetheless is surprising that the calculated energy difference between the two conformers on $\mathrm{Au}(111)$ is as high as $102 \mathrm{meV}$. This difference has two contributions. (i) The energies of the conformers differ by $40 \mathrm{meV}$ in the gas phase. This is most probably related to the HOMO being located on the arm with the dimethylaniline substituent (for all conformers). The conformational change of the first or second arm of the ligand have different (marginal) impact on the HOMO, notably revealed by the different HOMO energies $\left(E_{\mathrm{C}_{\mathrm{M}} \mathrm{T}_{\mathrm{F}}}^{H O M O}=-0.174 \mathrm{eV}\right.$ and $\left.E_{\mathrm{T}_{\mathrm{M}} \mathrm{C}_{\mathrm{F}}}^{H O M O}=-0.218 \mathrm{eV}\right)$. This in turn affects the total energy of the respective conformers. (ii) The adsorption energies of the two conformers differ by $62 \mathrm{meV}$, meaning that one rotated 

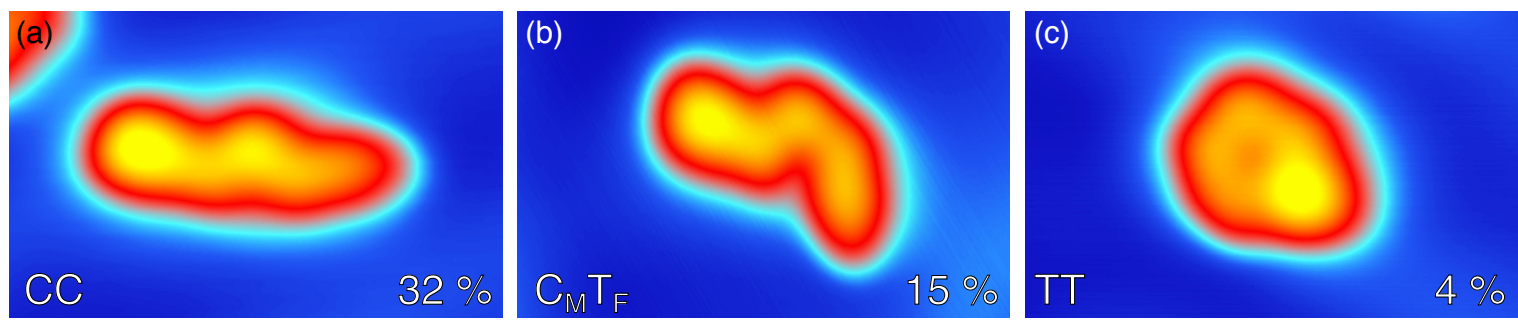

(d)
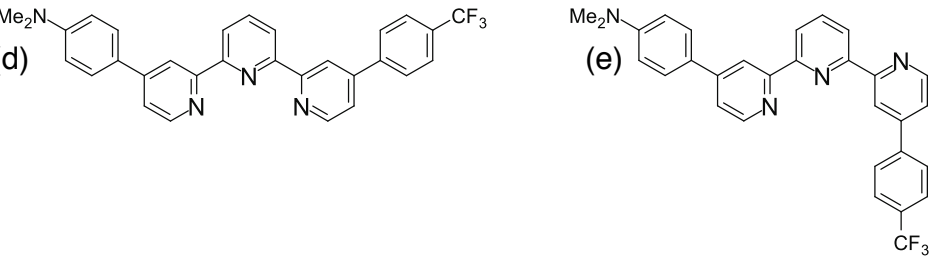

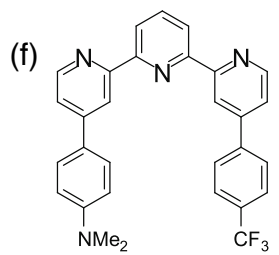

Figure 5: (a-c) Constant-current images (width: $4.5 \mathrm{~nm}$ ) of three distinct conformers of the tpy ligand on $\mathrm{Au}(111)$. Relative abundances of the conformers evaluated from 1021 ligands (isolated or within clusters) are indicated in the lower right of the images. $49 \%$ of the ligands are in the CC form with an Fe adatom in the vicinity (not shown). Tunneling parameters: $I=20 \mathrm{pA},(\mathrm{a}, \mathrm{b}) V=0.1 \mathrm{~V}$, (c) $V=0.3 \mathrm{~V}$. (d-f) Structural models of tpy conformers.

Table 1: Total energies of the tpy ligand in different conformations on a $\mathrm{Au}(111)$ slab calculated using Fireball and the LCAO-S ${ }^{2}+\mathrm{vdW}$ formalism. In the present case, gas phase refers to calculations on the isolated molecules (see methods). $E_{r e l}$ is the energy relative to the energy of the CC system. $E_{t o t}$ and $E_{a d s}$ refer to the total and adsorption energies, respectively.

\begin{tabular}{|c|c|c|c|c|c|}
\hline \multirow{2}{*}{ Conformation } & \multicolumn{2}{|c|}{ Gas phase } & \multicolumn{2}{|c|}{ Adsorbed } & \multirow{2}{*}{$E_{a d s}(\mathrm{eV})$} \\
\hline & $E_{t o t}(\mathrm{eV})$ & $E_{\text {rel }}(\mathrm{eV})$ & $E_{t o t}(\mathrm{eV})$ & $E_{r e l}(\mathrm{eV})$ & \\
\hline$\overline{\mathrm{CC}}$ & -7979.591 & 0 & -7981.138 & 0 & -1.547 \\
\hline $\mathrm{T}_{\mathrm{M}} \mathrm{C}_{\mathrm{F}}$ & -7979.699 & -0.108 & -7981.121 & 0.017 & -1.422 \\
\hline $\mathrm{C}_{\mathrm{M}} \mathrm{T}_{\mathrm{F}}$ & -7979.739 & -0.148 & -7981.224 & -0.085 & -1.484 \\
\hline $\mathrm{TT}$ & -7979.861 & -0.270 & -7981.467 & -0.330 & -1.606 \\
\hline
\end{tabular}

arm contributes slightly more to the adsoprtion energy, probably due to small steric effects.

Next, we consider the statistics of 1021 tpy ligands investigated on the $\mathrm{Au}(111)$ surface (Fig. 5). The calculated energies of the adsorbed tpy conformers do not reflect the experimentally observed occurrence. Indeed, by considering Boltzmann statistics at $300 \mathrm{~K}$, more than $99.9 \%$ of the ligands should be in the TT conformation. This suggests that thermodynamic equilibrium is not reached during sample preparation and therefore the energy barriers between the conformers play a role. To estimate the energy barrier for $\mathrm{CC}$ to $\mathrm{C}_{\mathrm{M}} \mathrm{T}_{\mathrm{F}}$ conformational change on $\mathrm{Au}(111)$ we calculated the total energy of a geometry with the trifluoromethyl substituted arm oriented normal to the surface $(-7980.019 \mathrm{eV})$. The estimated barrier is of the order to $1.2 \mathrm{eV}$, i.e. of same order as the adsorption energy of the ligand. This implies that the conformational change is unlikely to occur at room temperature for the ligand relaxed on $\mathrm{Au}(111)$. Furthermore, no conformational change was observed in molecular-dynamics simulation (25 ps time span, not shown) of the CC, $\mathrm{C}_{\mathrm{M}} \mathrm{T}_{\mathrm{F}}$ and $\mathrm{TT}$ conformers in the gas phase at $300 \mathrm{~K}$. As the energy barrier for tpy conformational change most likely is larger on the surface than in the gas phase, these simulations separately indicate that a relaxed tpy ligand on $\mathrm{Au}(111)$ is unlikely to undergo conformational changes. We therefore propose that the conformational change takes place before the kinetic energy of the ligand $(\approx 3 \mathrm{eV}$ for the entire molecule) is transferred to the $\mathrm{Au}(111)$ substrate. To check the validity of this hypothesis, we estimate the time scale required for the conformational change using molecular dynamics. Little is know about the state of the ligand before adsorption. We therefore simplified the system and solely considered a tpy ligand at a temperature of $600 \mathrm{~K}$. It is worth mentioning that molecular dynamics at reduced temperatures (300 and $450 \mathrm{~K}$ ) did not lead to a conformational change of the $\mathrm{CC}$ conformer. At $600 \mathrm{~K}$, conformational change occurs within 1.5 to 10 ps (data not shown). A similar timescale was reported for vibrational lifetimes of molecular adsorbates on metal substrates. ${ }^{58,59}$ The similarity of the timescales for conformational change and energy relaxation to the substrate suggests that they are effectively competing channels of energy relaxation. In turn, this is consistent with the observation of conformer abundances that do not correlate with their calculated energies. We emphasize that the DFT calcula- 
tions did not include intermolecular interactions, which may affect the conformer distribution. For completeness, similar molecular dynamics calculations were performed for complex 1 . No conformational changes of the ligands were observed. This independently supports the assumption that the proximity of an Fe atom stabilizes CC conformers.
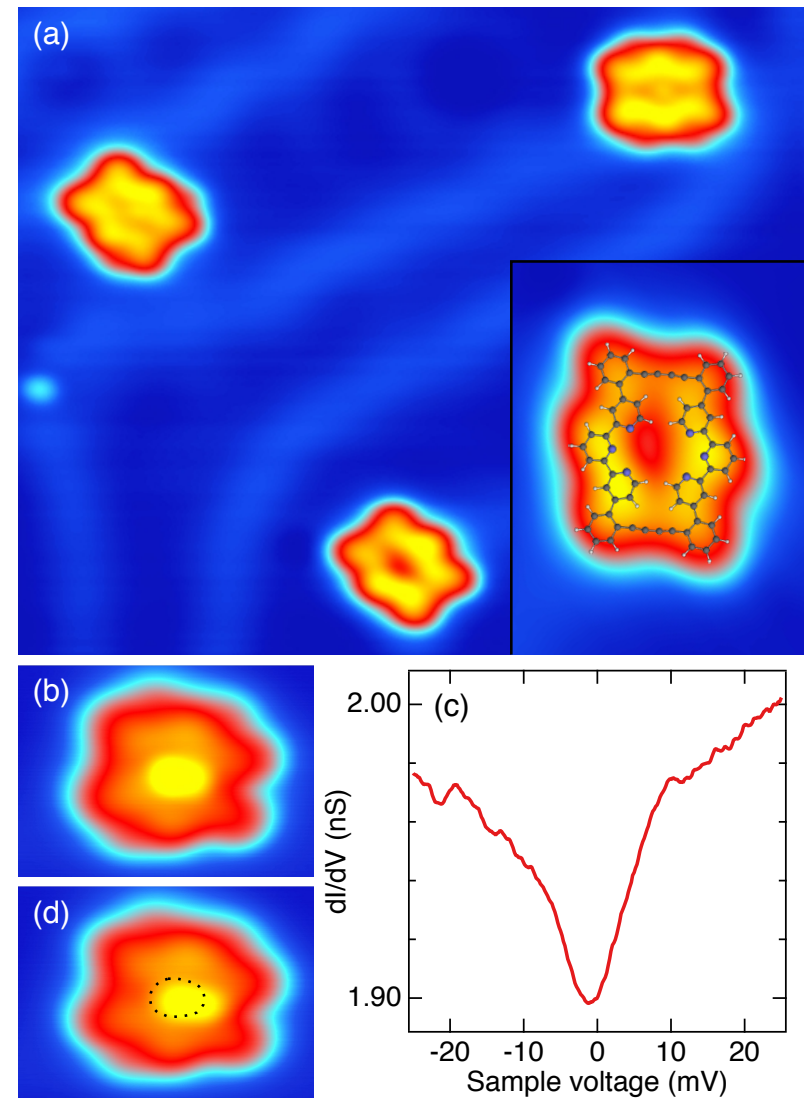

Figure 6: (a) STM topographs (width: $15.4 \mathrm{~nm}$, $V=100 \mathrm{mV}, I=100 \mathrm{pA}$ ) of complex 2 on $\mathrm{Au}(111)$. The inset is a detailed view of a single adsorbate with a superimposed molecular structure (width: $3 \mathrm{~nm}$, $V=100 \mathrm{mV}, I=200 \mathrm{pA}$ ). (b) STM topograph (width: $3.9 \mathrm{~nm}, V=100 \mathrm{mV}, I=20 \mathrm{pA}$ ) of a single adsorbate with a central protrusion. (c) Differential-conductance spectrum, acquired atop the protrusion center in (b), exhibiting a zero-bias feature (dip). (d) STM topograph (width: $3.9 \mathrm{~nm}, V=100 \mathrm{mV}, I=20 \mathrm{pA}$ ) of the same adsorbate as in (b) after having increased the sample voltage to $0.5 \mathrm{~V}$ with a current set point of $100 \mathrm{pA}$. The position of the central protrusion relative to the molecule changed.

Based on the fragmentation problems identified for complex 1, we designed and synthesized the reinforced complex 2 (Fig. 1) with symmetric phenyl-substituted ligands. Two 1,4-(diphenyl-2'-yl)-buta-1,3-diyne moieties (linker) attached to the terpyridine at the 4 and 4" position rigidly link the two tpy ligands while preserving the octahedral ligand sphere of the Fe center and the $\mathrm{N}$ atoms. The reinforced complex $\mathbf{2}$ was deposited on $\mathrm{Au}(111)$ using ESI. Typical mass spectra of the ion beam (not shown) display a clear peak due to intact $\mathbf{2}$, which was used for deposition. STM topographs of the deposited complex 2 exhibit two adsorbate structures (Figure 6), namely the macrocyclic ligand with and without the central Fe ion. Each adsorbate is comprised of two ligands in a cis-cis configuration. In contrast to the observations on complex $\mathbf{1}$, the ligand is symmetric as expected. Similar to complex 1, tpy ligands adopt a flat geometry on the $\mathrm{Au}(111)$ surface, incompatible with the gas-phase model of the molecule. We therefore infer that adsorption onto $\mathrm{Au}(111)$ deforms the $\mathrm{Fe}(\text { tpy })_{2}$ system $\mathbf{2}$ to a flat geometry (inset to Fig. 6a). Adsorbates with (upper adsorbates in Fig. 6a) and without (lower adsorbate in Fig. 6a) central protrusion are observed on the surface. Figure 6c shows a differential-conductance spectrum measured at the center of an adsorbate with a central protrusion (Fig. 6b). A clear zero-bias feature is discernible. Similar to complex 1, this feature could be the signature of a Kondo resonance. Although previous studies ${ }^{12,13,21}$ relied on Kondo resonances to address the spin states of adsorbed spin-crossover complexes, we refrain from doing so in the present case for two reasons. First, the flat adsorption of the tpy ligands significantly changes the symmetry and presumably the ligand field such that different spin states relative to the bulk compound may be expected. Second, the coordination of the Fe to the tpy ligand appears to be weak and unstable. Indeed, the position of the central Fe relative to the molecule was observed to easily change at moderate tunneling conditions $(V=0.5 \mathrm{~V}$ and $I=100 \mathrm{pA})$ as shown in Figures $6 \mathrm{~b}$ and $\mathrm{d}$.

It may be worth mentioning that only the molecular adsorbates shown in Figure 6 were observed on the $\mathrm{Au}(111)$ surface. In particular, all tpy ligands exhibit the cis-cis conformation. In the present case, the linker appears to have a double function: they prevent (i) conformational change of the tpy ligands, and (ii) a fragmentation of the dimer structure. Nonetheless, the intended preservation of the $\mathrm{Fe}(\mathrm{tpy})_{2}$ complex as SCO system is not achieved on the surface, presumably due to the influence of significant dispersion forces, which strongly flatten the molecules.

For the design of new robust SCO complexes, it appears essential to consider two aspects. (i) Reinforcement of the ligand structure to avoid fragmentation. This can notably be realized by effectively decreasing the number of ligands. For instance, complex $\mathbf{2}$ has effectively only one ligand whereas complex $\mathbf{1}$ is composed of two ligands. (ii) Reduce the planarity and size of the ligands to diminish van der Waals forces.

\section{Conclusions}

We investigated two $\mathrm{Fe}(\text { tpy) })_{2} \mathrm{SCO}$ complexes deposited on $\mathrm{Au}(111)$ using electrospray ionization. In both cases, the integrity of the molecule in the gas phase, before deposition, was verified by mass spectrometry. The first compound fragments upon deposition. All fragments 
on the surface could be identified as being due to $\mathrm{Fe}$ adatoms and conformers of the tpy ligands. From the abundances of different tpy conformers and the energetics inferred from DFT calculations, we conclude that the conformational change takes place early on during the adsorption process before the ligands have thermalized with the substrate. Conformational change of the tpy ligands is found to be unlikely when coordinated to the Fe ion. Consequently the fragmentation of the complex occurs before thermalization with the substrate. A complex stabilized by the linkers between the tpy ligands remains intact as desired. Combining two tridentate ligands to a single hexadentate shell turned out to be successful. However, the new complex is distorted compared to its gas-phase structure, presumably due to van der Waals forces. Taken together, the observations indicate that future molecular designs should aim at polydentate ligands while minimizing van der Waals forces.

Acknowledgement This project has received funding by the European Union's Horizon 2020 research and innovation programme under grant agreement No. 766726, by the Deutsche Forschungsgemeinschaft through SFB 677 and by the Swiss National Science Foundation (grant number: 200020-178808). C.G. acknowledges financial support from the Spanish Ministry of Science, Innovation and Universities through the project MAT2017-88258-R and María de Maeztu Programme for Units of Excellence in R\&D (MDM-20140377).

Note: The authors declare no competing financial interest.

\section{References}

(1) Halcrow, M. A. Spin-Crossover Materials Properties and Applications; J. Wiley and Sons, 2013.

(2) Bousseksou, A.; Molnár, G.; Demont, P.; Menegotto, J. Observation of a Thermal Hysteresis Loop in the Dielectric Constant of Spin Crossover Complexes: Towards Molecular Memory Devices. J. Mater. Chem. 2003, 13, 2069-2071.

(3) Molnár, G.; Cobo, S.; Real, J. A.; Carcenac, F.; Daran, E.; Vieu, C.; Bousseksou, A. A Combined Top-Down/Bottom-Up Approach for the Nanoscale Patterning of Spin-Crossover Coordination Polymers. Adv. Mater. 2007, 19, 2163.

(4) Bousseksou, A.; Molnár, G.; Salmon, L.; Nicolazzi, W. Molecular Spin Crossover Phenomenon: Recent Achievements and Prospects. Chem. Soc. Rev. 2011, 40, 3313-3335.

(5) Rotaru, A.; Dugay, J.; Tan, R. P.; Guralskiy, I. A.; Salmon, L.; Demont, P.; Carrey, J.;
Molnár, G.; Respaud, M.; Bousseksou, A. NanoElectromanipulation of Spin Crossover Nanorods: Towards Switchable Nanoelectronic Devices. Adv. Mater. 2013, 25, 1745-1749.

(6) Shepherd, H. J.; Gural'skiy, I. A.; Quintero, C. M.; Tricard, S.; Salmon, L.; Molnár, G.; Bousseksou, A. Molecular Actuators Driven by Cooperative Spin-State Switching. Nat. Commun. 2013, 4, 2607.

(7) Lefter, C.; Gural'skiy, I. A.; Peng, H.; Molnár, G.; Salmon, L.; Rotaru, A.; Bousseksou, A.; Demont, P. Dielectric and Charge Transport Properties of the Spin Crossover Complex $\left[\mathrm{Fe}(\mathrm{Htrz})_{2}(\mathrm{trz})\right]\left(\mathrm{BF}_{4}\right)$. Phys. Status Solidi 2013, 8, 191.

(8) Lefter, C.; Tan, R.; Dugay, J.; Tricard, S.; Molnár, G.; Salmon, L.; Carrey, J.; Rotaru, A.; Bousseksou, A. Light Induced Modulation of Charge Transport Phenomena Across the Bistability Region in $\left[\mathrm{Fe}(\mathrm{Htrz})_{2}(\mathrm{trz})\right]\left(\mathrm{BF}_{4}\right)$ Spin Crossover Micro-Rods. Phys. Chem. Chem. Phys. 2015, 17, 5151.

(9) Lefter, C.; Davesne, V.; Salmon, L.; Molnár, G.; Demont, P.; Rotaru, A.; Bousseksou, A. Charge Transport and Electrical Properties of Spin Crossover Materials: Towards Nanoelectronic and Spintronic Devices. Magnetochemistry 2016, 2, 18.

(10) Molnár, G.; Rat, S.; Salmon, L.; Nicolazzi, W.; Bousseksou, A. Spin Crossover Nanomaterials: From Fundamental Concepts to Devices. Adv. Mater. 2018, 30, 17003862.

(11) Schleicher, F.; Studniarek, M.; Kumar, K. S.; Urbain, E.; Katcko, K.; Chen, J.; Frauhammer, T.; Hervé, M.; Halisdemir, U.; Kandpal, L. M. et al. Linking Electronic Transport Through a Spin Crossover Thin Film to the Molecular Spin State Using X-Ray Absorption Spectroscopy Operando Techniques. ACS Appl. Mater. Interfaces 2018, 10, 31580-31585.

(12) Gopakumar, T. G.; Matino, F.; Naggert, H.; Bannwarth, A.; Tuczek, F.; Berndt, R. ElectronInduced Spin Crossover of Single Molecules in a Bilayer on Gold. Angew. Chem., Int. Ed. 2012, $51,6262-6266$.

(13) Miyamachi, T.; Gruber, M.; Davesne, V.; Bowen, M.; Boukari, S.; Joly, L.; Scheurer, F.; Rogez, G.; Yamada, T. K.; Ohresser, P. et al. Robust Spin Crossover and Memristance Across a Single Molecule. Nat. Commun. 2012, 3, 938. 
(14) Bernien, M.; Wiedemann, D.; Hermanns, C. F.; Krüger, A.; Rolf, D.; Kroener, W.; Müller, P.; Grohmann, A.; Kuch, W. Spin Crossover in a Vacuum-Deposited Submonolayer of a Molecular Iron(II) Complex. J. Phys. Chem. Lett. 2012, 3, 3431-3434.

(15) Gopakumar, T. G.; Bernien, M.; Naggert, H.; Matino, F.; Hermanns, C. F.; Bannwarth, A.; Mühlenberend, S.; Krüger, A.; Krüger, D.; Nickel, F. et al. Spin-Crossover Complex on $\mathrm{Au}(111)$ : Structural and Electronic Differences Between Mono- And Multilayers. Chem. Eur. J. 2013, 19, 15702-15709.

(16) Warner, B.; Oberg, J. C.; Gill, T. G.; El Hallak, F.; Hirjibehedin, C. F.; Serri, M.; Heutz, S.; Arrio, M.A.; Sainctavit, P.; Mannini, M. et al. TemperatureAnd Light-Induced Spin Crossover Observed by XRay Spectroscopy on Isolated Fe(II) Complexes on Gold. J. Phys. Chem. Lett. 2013, 4, 1546-1552.

(17) Gruber, M.; Davesne, V.; Bowen, M.; Boukari, S.; Beaurepaire, E.; Wulfhekel, W.; Miyamachi, T. Spin State of Spin-Crossover Complexes: From Single Molecules to Ultrathin Films. Phys. Rev. B 2014, 89, 195415.

(18) Bernien, M.; Naggert, H.; Arruda, L. M.; Kipgen, L.; Nickel, F.; Miguel, J.; Hermanns, C. F.; Krüger, A.; Krüger, D.; Schierle, E. et al. Highly Efficient Thermal and Light-Induced Spin-State Switching of an Fe(II) Complex in Direct Contact With a Solid Surface. ACS Nano 2015, 9, 8960-8966.

(19) Gueddida, S.; Gruber, M.; Miyamachi, T.; Beaurepaire, E.; Wulfhekel, W.; Alouani, M. Exchange Coupling of Spin-Crossover Molecules to Ferromagnetic Co Islands. J. Phys. Chem. Lett. 2016, 7, 900-904.

(20) Bairagi, K.; Iasco, O.; Bellec, A.; Kartsev, A.; Li, D.; Lagoute, J.; Chacon, C.; Girard, Y.; Rousset, S.; Miserque, F. et al. Molecular-Scale Dynamics of Light-Induced Spin Cross-Over in a Two-Dimensional Layer. Nat. Commun. 2016, 7 , 12212

(21) Gruber, M.; Miyamachi, T.; Davesne, V.; Bowen, M.; Boukari, S.; Wulfhekel, W.; Alouani, M.; Beaurepaire, E. Spin Crossover in $\mathrm{Fe}(\text { phen })_{2}(\mathrm{NCS})_{2}$ Complexes on Metallic Surfaces. J. Chem. Phys. 2017, 146, 092312.

(22) Jasper-Tönnies, T.; Gruber, M.; Karan, S.; Jacob, H.; Tuczek, F.; Berndt, R. Deposition of a Cationic $\mathrm{Fe}^{\mathrm{III}}$ Spin-Crossover Complex on $\mathrm{Au}(111)$ : Impact of the Counter Ion. J. Phys. Chem. Lett. 2017, 8, 1569-1573.
(23) Jasper-Toennies, T.; Gruber, M.; Karan, S.; Jacob, H.; Tuczek, F.; Berndt, R. Robust and Selective Switching of an $\mathrm{Fe}^{\mathrm{III}}$ Spin-Crossover Compound on $\mathrm{Cu}_{2} \mathrm{~N} / \mathrm{Cu}(100)$ With Memristance Behavior. Nano Lett. 2017, 17, 6613.

(24) Kipgen, L.; Bernien, M.; Nickel, F.; Naggert, H.; Britton, A. J.; Arruda, L. M.; Schierle, E.; Weschke, E.; Tuczek, F.; Kuch, W. Soft-X-RayInduced Spin-State Switching of an Adsorbed Fe(II) Spin-Crossover Complex. J. Phys.: Condens. Matter 2017, 29, 394003.

(25) Kuch, W.; Bernien, M. Controlling the Magnetism of Adsorbed Metalextendashorganic Molecules. $J$. Phys.: Condens. Matter 2017, 29, 023001.

(26) Ossinger, S.; Naggert, H.; Kipgen, L.; JasperToennies, T.; Rai, A.; Rudnik, J.; Nickel, F.; Arruda, L. M.; Bernien, M.; Kuch, W. et al. VacuumEvaporable Spin-Crossover Complexes in Direct Contact With a Solid Surface: Bismuth Versus Gold. J. Phys. Chem. C 2017, 121, 1210-1219.

(27) Bairagi, K.; Bellec, A.; Fourmental, C.; Iasco, O.; Lagoute, J.; Chacon, C.; Girard, Y.; Rousset, S.; Choueikani, F.; Otero, E. et al. Temperature-, Light-, and Soft X-Ray-Induced Spin Crossover in a Single Layer of FeII-Pyrazolylborate Molecules in Direct Contact With Gold. J. Phys. Chem. C 2017, 122, 727 .

(28) Kipgen, L.; Bernien, M.; Ossinger, S.; Nickel, F.; Britton, A. J.; Arruda, L. M.; Naggert, H.; Luo, C.; Lotze, C.; Ryll, H. et al. Evolution of Cooperativity in the Spin Transition of an Iron(II) Complex on a Graphite Surface. Nat. Commun. 2018, 9, 2984.

(29) Shi, S.; Schmerber, G.; Arabski, J.; Beaufrand, J.B.; Kim, D. J.; Boukari, S.; Bowen, M.; Kemp, N. T.; Viart, N.; Rogez, G. et al. Study of Molecular Spin-Crossover Complex $\mathrm{Fe}(\mathrm{phen})_{2}(\mathrm{NCS})_{2}$ Thin Films. Appl. Phys. Lett. 2009, 95, 043303.

(30) Naggert, H.; Bannwarth, A.; Chemnitz, S.; von Hofe, T.; Quandt, E.; Tuczek, F. First Observation of Light-Induced Spin Change in Vacuum Deposited Thin Films of Iron Spin Crossover Complexes. Dalton Trans. 2011, 40, 6364-6366.

(31) Mahfoud, T.; Molnár, G.; Cobo, S.; Salmon, L.; Thibault, C.; Vieu, C.; Demont, P.; Bousseksou, A. Electrical Properties and Non-Volatile Memory Effect of the $\left[\mathrm{Fe}\left(\mathrm{HB}(\mathrm{pz})_{3}\right)_{2}\right]$ Spin Crossover Complex Integrated in a Microelectrode Device. Appl. Phys. Lett. 2011, 99, 053307. 
(32) Palamarciuc, T.; Oberg, J. C.; El Hallak, F.; Hirjibehedin, C. F.; Serri, M.; Heutz, S.; Létard, J. F.; Rosa, P. Spin Crossover Materials Evaporated Under Clean High Vacuum and Ultra-High Vacuum Conditions: From Thin Films to Single Molecules. J. Mater. Chem. 2012, 22, 9690-9695.

(33) Molnár, G.; Salmon, L.; Nicolazzi, W.; Terki, F.; Bousseksou, A. Emerging Properties and Applications of Spin Crossover Nanomaterials. J. Mater. Chem. C 2014, 2, 1360.

(34) Davesne, V.; Gruber, M.; Studniarek, M.; Doh, W. H.; Zafeiratos, S.; Joly, L.; Sirotti, F.; Silly, M. G.; Gaspar, A. B.; Real, J. A. et al. Hysteresis and Change of Transition Temperature in Thin Films of $\mathrm{Fe}\left\{\left[\mathrm{Me}_{2} \mathrm{Pyrz}\right]_{3} \mathrm{BH}\right\}_{2}$, a New Sublimable Spin-Crossover Molecule. J. Chem. Phys. 2015, 142, 194702.

(35) Iasco, O.; Boillot, M.-L.; Bellec, A.; Guillot, R.; Rivière, E.; Mazerat, S.; Nowak, S.; Morineau, D.; Brosseau, A.; Miserque, F. et al. The Disentangling of Hysteretic Spin Transition, Polymorphism and Metastability in Bistable Thin Films Formed by Sublimation of Bis(scorpionate) Fe(II) Molecules. J. Mater. Chem. C 2017, 5, 11067.

(36) Rohlf, S.; Gruber, M.; Flöser, B. M.; Grunwald, J.; Jarausch, S.; Diekmann, F.; Kalläne, M.; JasperToennies, T.; Buchholz, A.; Plass, W. et al. LightInduced Spin Crossover in an Fe(II) Low-Spin Complex Enabled by Surface Adsorption. J. Phys. Chem. Lett. 2018, 9, 1491-1496.

(37) Kumar, K. S.; Studniarek, M.; Heinrich, B.; Arabski, J.; Schmerber, G.; Bowen, M.; Boukari, S.; Beaurepaire, E.; Dreiser, J.; Ruben, M. Engineering On-Surface Spin Crossover: Spin-State Switching in a Self-Assembled Film of VacuumSublimable Functional Molecule. Adv. Mater. 2018, 30, 1705416.

(38) Harzmann, G. Novel Tailor-Made Externally Triggerable Single-Molecular Switches for Molecular Electronics. Ph.D. thesis, Universität Basel, 2014.

(39) Brandl, T.; Hoffmann, V.; Pannwitz, A.; Häussinger, D.; Neuburger, M.; Fuhr, O.; Bernhard, S.; Wenger, O. S.; Mayor, M. Chiral Macrocyclic Terpyridine Complexes. Chem. Sci. 2018, 9, 3837-3843.

(40) Harzmann, G. D.; Neuburger, M.; Mayor, M. 4,4'Disubstituted Terpyridines and Their Homoleptic $\mathrm{Fe}^{\mathrm{II}}$ Complexes. Eur. J. Inorg. Chem. 2013, 2013, 3334-3347.

(41) Harzmann, G. D.; Frisenda, R.; Zant, H. S. J. v. d.; Mayor, M. Single-Molecule Spin Switch Based on Voltage-Triggered Distortion of the Coordination
Sphere. Angew. Chem., Int. Ed. 2015, 54, 1342513430.

(42) Hamann, C.; Woltmann, R.; Hong, I.-P.; Hauptmann, N.; Karan, S.; Berndt, R. Ultrahigh Vacuum Deposition of Organic Molecules by Electrospray Ionization. Rev. Sci. Instrum. 2011, 82, 033903.

(43) Karan, S.; Hamann, C.; Tang, H.; Stefankiewicz, A. R.; Lehn, J.-M.; Berndt, R. Surface Trapping and STM Observation of Conformational Isomers of a Bis(Terpyridine) Ligand From Metallosupramolecular Grids. Chem. Phys. Chem 2015, 1370 .

(44) Knaak, T.; Gruber, M.; Lindström, C.; Bocquet, M.-L.; Heck, J.; Berndt, R. Ligand-Induced Energy Shift and Localization of Kondo Resonances in Cobalt-Based Complexes on $\mathrm{Cu}(111)$. Nano Lett. 2017, 17, 7146.

(45) Knaak, T.; Gruber, M.; Puhl, S.; Benner, F.; Escribano, A.; Heck, J.; Berndt, R. Interconnected Cobaltocene Complexes on Metal Surfaces. J. Phys. Chem. C 2017, 121, 26777-26784.

(46) Horcas, I.; Fernández, R.; GómezRodríguez, J. M.; Colchero, J.; Gómez-Herrero, J.; Baro, A. M. WSXM: A software for scanning probe microscopy and a tool for nanotechnology. Rev. Sci. Instrum. 2007, 78, 013705.

(47) Lewis, J. P.; Jelínek, P.; Ortega, J.; Demkov, A. A.; Trabada, D. G.; Haycock, B.; Wang, H.; Adams, G.; Tomfohr, J. K.; Abad, E. et al. Advances and Applications in the FIRE$\mathrm{BALL} \mathrm{Ab}$ Initio Tight-Binding MolecularDynamics Formalism. Phys. Status Solidi (b) 2011, 248, 1989-2007.

(48) Pham, V. D.; Repain, V.; Chacon, C.; Bellec, A.; Girard, Y.; Rousset, S.; Abad, E.; Dappe, Y. J.; Smogunov, A.; Lagoute, J. Tuning the Electronic and Dynamical Properties of a Molecule by Atom Trapping Chemistry. ACS Nano 2017, 11, 1074210749 .

(49) Basanta, M. A.; Dappe, Y. J.; Jelínek, P.; Ortega, J. Optimized Atomic-Like Orbitals for First-Principles Tight-Binding Molecular Dynamics. Comput. Mater. Sci. 2007, 39, 759-766.

(50) Dappe, Y. J.; Basanta, M. A.; Flores, F.; Ortega, J. Weak Chemical Interaction and Van Der Waals Forces Between Graphene Layers: A Combined Density Functional and Intermolecular Perturbation Theory Approach. Phys. Rev. B 2006, $74,205434$. 
(51) González, C.; Abad, E.; Dappe, Y. J.; Cuevas, J. C. Theoretical Study of CarbonBased Tips for Scanning Tunnelling Microscopy. Nanotechnology 2016, 27, 105201.

(52) Frisenda, R.; Harzmann, G. D.; Celis Gil, J. A.; Thijssen, J. M.; Mayor, M.; van der Zant, H. S. J. Stretching-Induced Conductance Increase in a Spin-Crossover Molecule. Nano Lett. 2016, 16, 4733-4737.

(53) Burtzlaff, A.; Weismann, A.; Brandbyge, M.; Berndt, R. Shot Noise as a Probe of Spin-Polarized Transport Through Single Atoms. Phys. Rev. Lett. 2015, 114, 016602.

(54) Gruber, M.; Weismann, A.; Berndt, R. The Kondo Resonance Line Shape in Scanning Tunnelling Spectroscopy: Instrumental Aspects. J. Phys. Condens. Matter 2018, 30, 424001.

(55) Jamneala, T.; Madhavan, V.; Chen, W.; Crommie, M. F. Scanning Tunneling Spectroscopy of Transition-Metal Impurities at the Surface of Gold. Phys. Rev. B 2000, 61, 9990-9993.

(56) Karan, S.; García, C.; Karolak, M.; Jacob, D.; Lorente, N.; Berndt, R. Spin Control Induced by Molecular Charging in a Transport Junction. Nano Lett. 2018, 18, 88-93.

(57) Khajetoorians, A. A.; Valentyuk, M.; Steinbrecher, M.; Schlenk, T.; Shick, A.; Kolorenc, J.; Lichtenstein, A. I.; Wehling, T. O.; Wiesendanger, R.; Wiebe, J. Tuning Emergent Magnetism in a Hund's Impurity. Nat. Nanotech. 2015, 10, 958-964.

(58) Harris, A. L.; Rothberg, L.; Dhar, L.; Levinos, N. J.; Dubois, L. H. Vibrational Energy Relaxation of a Polyatomic Adsorbate on a Metal Surface: Methyl Thiolate $\left(\mathrm{CH}_{3} \mathrm{~S}\right)$ on $\mathrm{Ag}(111)$. J. Chem. Phys. 1991, 94, 2438-2448.

(59) Morin, M.; Levinos, N. J.; Harris, A. L. Vibrational Energy Transfer of $\mathrm{CO} / \mathrm{Cu}(100)$ : Nonadiabatic Vibration/Electron Coupling. J. Chem. Phys. 1992, 96, 3950-3956. 


\section{Graphical TOC Entry}

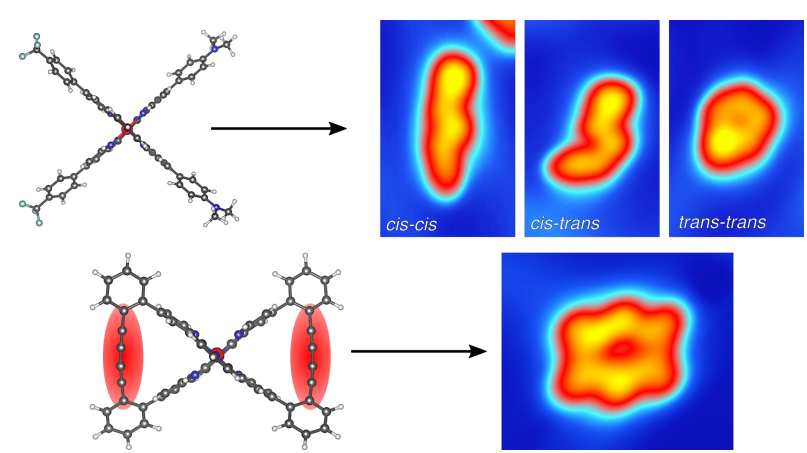

